\title{
TODA HISTÓRIA COMEÇA IN MEDIA RES: NIETZSCHE E AS CIÊNCIAS DA LINGUAGEM
}

\section{EVERY STORY BEGINS IN MEDIA RES: NIETZSCHE AND LANGUAGE SCIENCES}

\author{
Isadora Lima Machado \\ Universidade Federal da Bahia, UFBA, Salvador, BA, Brasil
}

\begin{abstract}
Resumo: A partir da perspectiva da História das Ideias Linguísticas, investigamos as filiaçōes a Friedrich Wilhelm Nietzsche nas Ciências da Linguagem. A hipótese do trabalho é a de que a enunciação nietzscheana é um acontecimento na história da reflexão sobre a linguagem. Compreende-se acontecimento tal como o define Eduardo Guimarães: não enquanto um fato no tempo, mas como aquilo que produz diferença em sua própria ordem. Tomada como acontecimento, a enunciação nietzscheana instaura sua própria diferença, e nela consideramos duas temporalidades distintas: por um lado, a que produz a filiaçấo de Edward Sapir a Nietzsche, e que recorta Wilhelm von Humboldt como memorável; por outro, a que produz a filiação de Michel Pêcheux a Nietzsche. A possibilidade de pensar as temporalidades em sua equivocidade demonstra que há um caminho na reflexão sobre a linguagem a ser trilhado nas sendas de um materialismo trágico - a consideração de que a determinação histórica não é fruto de um processo maquínico, motorizado, mas que há algo do acaso que comparece.
\end{abstract}

Palavras-Chave: Nietzsche; Acontecimento; Ciências da Linguagem.

Abstract: From the perspective of the History of the Linguistic Ideas, this work investigates the affiliations to Friedrich Wilhelm Nietzsche in Language Sciences. The hypothesis of this work is that Nietzsche's enunciation is an event in the history of the reflection on language. We understand the event, as defined by Eduardo Guimarães, i.e., not as a fact in time, but as something that produces a difference in its own order. Taken as an event, Nietzsche's enunciation establishes its own difference, and in it we consider two different time frames: on the one hand, the one that produces Edward Sapir's affiliation to Nietzsche, and that highlights Wilhelm von Humboldt as memorable; on the other hand, the one that produces Pêcheux's affiliation to Nietzsche. The possibility of thinking temporalities in its own equivocity demonstrates that there is a path in the reflection on language to be taken in the paths of a tragic materialism - the consideration that the historical determination is not a result of a machine and motorized process, but that there is something from chance that appears, and that, in that chance, an interval between the misunderstanding and the language, there is still a space for art, for creation, to r-exist to the sedentary senses.

Key-Words: Nietzsche; Event; Language Sciences. 
Why has someone, declared to be a philologist of genius, appointed Professor of Philology - as the professional study of language, was then know - at the University of Basel at twenty-four, given his doctorate with examination exempted by Leipzig, birthplace of comparative linguistics, why has Nietzsche had so little to do with subsequent linguistics?

R. Chatterjee ${ }^{1}$

\section{Introduçáo}

Há muito a pergunta que epigrafa este artigo deixou de ser nossa questáo. Ter deixado de ser implica o já ter sido. Não nos surpreende que tenha sido, durante algum tempo, precisamente esta a nossa questáo. Nela funciona um raciocínio bastante sedutor, aquele cujo pressuposto é o de que: se X... logo, necessariamente, Y. Algo que diz respeito à lógica de causa e efeito talvez esperada em uma concepção escatológica da História: se a Linguística já foi outrora Filologia e Linguística Comparada, então por que um grandioso filólogo, formado no berço do comparatismo, náo teve seu nome gravado nos livros de história da Linguística?

A disciplina de História das Ideias Linguisticas, tal como é teorizada e produzida no Brasil, fez com que, de outra perspectiva, a pergunta também fosse outra. Ao invés de nos perguntar pela causa - por que Nietzsche não foi lido na Linguística - passamos a nos perguntar pelas condiçóes: sob que condições pode Nietzsche ser filiado à História das Ideias Linguísticas? O que condiciona a possibilidade da presença de Nietzsche neste domínio? Que condiçôes Nietzsche possibilita na Linguística?

A partir dessa mudança, foi necessário que o problema fosse colocado de outro lugar. Passamos então a ter em vista que as fronteiras entre o conhecimento são imaginárias, mas que nem por isso (inclusive por isso) deixam de produzir seus efeitos. De início percebemos que eram condições bastante particulares estas de Nietzsche nas Ciências da Linguagem. Particulares porque, para o bem e para o mal, o nome do filósofo alemão correu várias áreas nas Ciências Humanas e sempre esteve inclusive bem próximo dos teóricos e cientistas da literatura. Muitos foram os intelectuais que ao longo do século XX reivindicaram a filiação a Nietzsche, ou mesmo que se filiaram a outros

${ }^{1}$ CHATTERJEE, R. Before and beyond Linguistics: Professor Nietzsche, Philologist. In: NICHOLSON, C.; CHATTERJEE, R. Tropic crucible: self and theory in language and literature. Kent Ridge, Singapore: Singapore University Press, 1984. p. 24-35. 
pensadores, em função de não quererem se filiar a Nietzsche.

Em Para além das palavras e das coisas: Nietzsche e as Ciências da Linguagem ${ }^{2}$, investigamos a filiação ${ }^{3}$ entre Nietzsche e o que foi chamado de Hipótese Sapir-Whorf. O estudo dessa filiação apontou para uma disparidade entre o pensamento de Sapir e o de Whorf, disparidade esta que veio à tona quando concluímos que, se Sapir poderia ser filiado a Nietzsche, Whorf, por sua vez, não permitia essa filiação. Disso decorreu que não fazia mais sentido falar de uma Hipótese Sapir-Whorf, a não ser para abarcar um conjunto de definiçóes díspares, que muitas vezes se anulavam.

Nesse estudo havia ficado clara a filiação entre Nietzsche e Sapir, que passava inclusive pela noçáo de hábito gramatical, hábito linguístico. Nas Ciências da Linguagem, entretanto, os livros de história da linguística remetiam sempre a hipótese a Guilherme de Humboldt, o que nos levou a pensar que poderia haver algo de Humboldt que comparecesse em Nietzsche a ponto de ambos se fazerem presentes no pensamento de Sapir. De fato, veremos que essa é uma relação possível, mas não a ponto de Humboldt ser condição para a existência do pensamento de Nietzsche.

Nietzsche era um nome que também aparecia espaçadamente em algumas ocasiôes na obra de Michel Pêcheux, e a filiaçáo entre os dois também foi indicada em textos de outros autores, como Denise Maldidier e Paul Henry. Isso a tal ponto que tentamos configurar de que modo um poderia ser filiado ao outro. $\mathrm{O}$ esboço dessa tentativa nos levou, de modo inconsciente, a expressá-la por meio de termos que haviam sido cunhados por Eni Orlandi. A percepção desse mecanismo é que nos conduziu a estudar essa filiação de modo mais detido. Neste artigo, entretanto, trataremos apenas da filiação entre Nietzsche e Pêcheux no que tange à Análise de Discurso..

\footnotetext{
${ }^{2}$ MACHADO, Isadora Lima. Para além das palavras e das coisas: Friedrich W. Nietzsche e as Ciências da Linguagem. 2011. 167 p. Dissertação (mestrado) - Universidade Estadual de Campinas, Instituto de Estudos da Linguagem, Campinas, SP. Disponível em: <http://www. repositorio.unicamp.br/handle/REPOSIP/270583>. Acesso em: 05 mai. 2018.

${ }^{3}$ Entendemos por filiaçấo o resultado de um gesto interpretativo por parte do analista que visa a estabelecer a procedência (marcas subindividuais que se organizam em rede) e a emergência (cena de distribuição de conceitos) de relaçóes de sentido interdependentes entre ideias, textos, autores e funcionamentos enunciativos e/ou discursivos. Procedência e emergência são interpretaçôes que Michel Foucault produz a partir da leitura de Genealogia da Moral, de Nietzsche. Está no texto "Nietzsche, a genealogia, e a história", publicado no Brasil em Microfísica do Poder (NIETZSCHE, [1979] 2008).
} 
Se levássemos em conta o tempo cristáo, linear e escatológico, seria preciso dizer que tudo começa em Humboldt. Caminha até Nietzsche. Encontra então Sapir. Chega a Pêcheux, que, por sua vez, chega a Orlandi (por mais que os dois sejam contemporâneos). Encarar o tempo como uma linha que progride nos levaria a contar essa história de modo bastante simples: o mais antigo influencia o que é mais novo e isso se acumula, o acúmulo de conhecimento gerado pelos dois é recebido por um terceiro, que se junta e influencia um quarto, e daí por diante.

Nosso trabalho, entretanto, é a tentativa de se inscrever em um lugar de dizer que rompa as cadeias lineares e se aproxime de um trabalho nietzscheano, que leve em conta a emergência e a procedência dos nomes, em detrimento da busca pela origem.

\section{Uma temporalidade: Nietzsche-Pêcheux}

Denise Maldidier (1990, p. 91, grifos nossos), em L'inquiétude du discours, afirma: "Il a travaillé d'impossibles 'machines à lire' qui allaient ouvrir de nouvelles lectures. Il a infatigablement lu ou relu donné à lire,

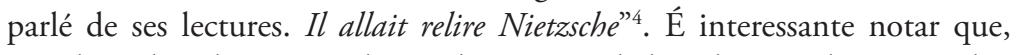
na edição brasileira, a tradução diz que Michel Pêcheux ia ler Nietzsche. Acreditamos que esse detalhe de tradução diz muito. Afinal, se ele iria ler, não se poderia dizer qual caminho Pêcheux tomaria nessa leitura. Se, entretanto, ele iria reler, podemos pensar de modo mais material nessa relação. Buscaremos, então, demonstrar parte dessa possível relaçáo entre Nietzsche e Pêcheux, particularmente no que tange à crítica do sujeito lógico.

Nietzsche instaurou com sua filosofia o que podemos chamar de crítica ao sujeito das proposiçôes, ou sujeito lógico. O sujeito, na filosofia nietzscheana, é uma ficção e, enquanto ficção, passível de genealogia, de desconstrução. Um pensamento, segundo Nietzsche ([1886] 2005, §17), vem quando ele quer e não quando eu quero, de modo que é um falseamento da realidade atribuir ao predicado "penso" o sujeito "eu". Trata-se de um hábito gramatical. Assim, onde os filósofos enxergam uma categoria filosófica, a de sujeito, Nietzsche afirma ser apenas uma categoria gramatical que induz o raciocínio dos filósofos. A crença no sujeito lógico é apenas uma crença metafísica.

${ }^{4}$ Traduçấo nossa: "Ele trabalhou 'máquinas de ler' impossíveis, que levaram a outras leituras. Ele incansavelmente leu ou releu, deu a ler, falou de suas leituras. Ele ia reler Nietzsche.” 
Ao problema do sujeito se liga o problema da consciência. Por meio da crítica ao sujeito lógico, Nietzsche opera entấo o descentramento do sujeito, pois náo agimos onde tencionamos. Quando Nietzsche instaura a condição opositiva entre a ação e a consciência, tecida pelo trabalho da linguagem, para ele não se trata da velha oposição entre sujeito e objeto, pois essa distinção ele deixa "para os teóricos do conhecimento que se enredaram nas teias da gramática (a metafísica do povo)" (NIETZSCHE, [1882] 2008, \$ 354). Não se trata, de igual maneira, da oposição entre fenômeno e coisa em si, "pois estamos longe de 'conhecer' o suficiente para poder assim separar" (NIETZSCHE, [1882] 2008, \$354).

A gramática, e assim o sujeito gramatical, exerce o papel de metafísica do povo. A linguagem, nesse contexto, é a responsável por tornar ordinária a experiência individual, por banalizá-la, uma vez que para as infinitas possibilidades do sentir e do fazer, temos um conjunto limitado de palavras. É por isso que Nietzsche tomará também a gramática como uma das razóes para toda a dogmatização em filosofia (NIETZSCHE, [1886] 2005, Prólogo). Eis a receita que Nietzsche identifica em todo e qualquer edifício filosófico construído pelos dogmáticos:

[...] alguma superstiçấo popular de um tempo imemorial (como a superstição da alma, que, como superstição do sujeito e do Eu, ainda hoje causa danos), talvez algum jogo de palavras, alguma sedução (Verführung) por parte da gramática, ou temerária generalização de fatos muito estreitos, muito pessoais, demasiado humanos [...] (NIETZSCHE, [1886] 2005, Prólogo).

É interessante notar que, para Nietzsche, a noção de alma pode ser derivada da noção supersticiosa do sujeito e do eu, ambos como atomismos. Todas as três noçóes são superstições populares de tempos imemoriais e, além delas, entra em cena também algum jogo de palavras e os desencaminhamentos provocados pela gramática. Esse poder da linguagem de instaurar uma interpretação do mundo é tido por Nietzsche como causa, por exemplo, do erro de Descartes e de tantos outros filósofos: eles foram seduzidos pela gramática.

"Eu quero", como era superstição de Schopenhauer, ou "eu penso", como foi a superstição de Descartes. Essas certezas foram tidas como imediatas partindo do preconceito de que nem no que tange ao sujeito e nem no que tange ao objeto houvesse uma falsificação. Para Nietzsche, nos termos "certeza imediata", "conhecimento absoluto" e "coisa em si" há um contra- 
dictio in adjeto, e por isso "deveríamos nos livrar, de uma vez por todas, da sedução das palavras!” (NIETZSCHE, [1886] 2005, \$16). O filósofo deveria propor-se uma atitude diferente da atitude do povo, que acredita que conhecer pode significar conhecer até o fim. O filósofo precisa colocar em suspeita a linguagem: se o filósofo decompóe as proposiçóes "eu penso" ou "eu quero", perceberá que delas decorrem uma série de afirmaçóes de difícil sustentaçáo: "que sou eu que pensa, que tem de haver necessariamente um algo impossível que pensa, que pensar é atividade e efeito de um ser que é pensado como causa, que existe um "eu", e finalmente que já está estabelecido o que designar como pensar - que eu sei o que é pensar" (NIETZSCHE, [1886] 2005, \$ 16). Como se pode saber que a ação é pensar, e não sentir ou querer? Afirmar "eu penso" pressuporia que, ao comparar o estado momentâneo em que me encontro com outros estados que conheço de mim, se poderia afirmar o que este estado é, de modo que eu penso não pode ser tomado como uma certeza imediata. Neste caso, o filósofo se depara com uma série de problemas metafísicos: "de onde retiro o conceito de pensar? Por que acredito em causa e efeito? O que me dá o direito de falar de um Eu, e até mesmo de um Eu como causa, e por fim de um Eu como causa de pensamentos?” (NIETZSCHE, [1886] 2005, \$16).

Conforme já mencionamos, o pensar enquanto consequência de um sujeito, eu, para Nietzsche é apenas uma superstição dos lógicos ([1886] $2005, \$ 17)$. O que estes não levam em conta é que um pensamento surge quando ele quer, e não quando o eu quer, "de modo que é um falseamento da realidade efetiva dizer: o sujeito "eu" é a condição do predicado 'penso"” (NIETZSCHE, [1886] 2005, \$17). Dizer que isso (es, em alemão; it, em inglês) pensa já é ir longe demais, mas mesmo assim, que esse isso seja "o velho e decantado eu" é apenas uma suposição, nunca uma certeza imediata. O isso enquanto causa de penso já é uma interpretação do processo.

Nessa interpretaçáo, o sujeito enquanto causa e o predicado enquanto efeito, conclui-se segundo um hábito gramatical: "pensar é uma atividade, toda atividade requer um agente, logo -" (NIETZSCHE, [1886] 2005, $\$ 17)$. Ou seja, determinado a partir de uma forma de raciocínio de uma gramática específica, o filósofo empreende uma interpretação do mundo. Interpretaçáo esta condicionada pela linguagem e todo seu aparato de hábitos gramaticais.

Nesse contexto, Nietzsche ([1886] 2005, \$19) dirá que muitas vezes apenas a palavra garante a unidade da coisa. Quando os filósofos falam, por exemplo, de vontade, tomam-na enquanto unidade. Quando Schopenhauer 
afirma que "apenas a vontade é conhecida por nós" (NIETZSCHE, [1886] 2005 , \$19), ele apenas toma um preconceito popular e o exagera. O querer, para Nietzsche, é antes de tudo algo complicado, pois é constituído, minimamente, por duas partes: uma que comanda e uma que obedece. E, linguisticamente, tratamos isso de eu, conceito sintético para a pluralidade da coisa.

Em Genealogia da moral, na primeira dissertaçáo, o problema da sedução da linguagem reaparece para dizer que

\begin{abstract}
nada mais é senão este mesmo impulso, este mesmo querer e atuar, e apenas sob a sedução da linguagem (e dos erros fundamentais da razão que nela se petrificaram), a qual entende ou mal-entende que todo atuar é determinado por um atuante, um 'sujeito', é que pode parecer diferente (NIETZSCHE, [1887] 2004, I, \$ 13).
\end{abstract}

Nesse sentido, apenas sob a sedução da linguagem é que se pode não compreender que a força é sempre um querer-atuar, sem sujeito. Para Nietzsche, não existe ser por trás do devir e nesse sentido o sujeito, "o agente", é apenas uma ficção que foi agregada à ação. Em contrapartida, os cientistas tomam a mesma superstição popular ao dizer "a força movimenta, a força origina”, e assim por diante - toda a nossa ciência se encontra sob a sedução da linguagem, não obstante seu sangue-frio, sua indiferença aos afetos, e ainda se livrou dos falsos filhos que lhe empurraram, os "sujeitos" (o átomo, por exemplo, é uma dessas falsas crias, e também a "coisa em si" kantiana)" (NIETZSCHE, [1887] 2004, I, \$13). A crença no sujeito, enquanto crença no eu ou na alma, foi o artigo de fé mais petrificado pela sedução da linguagem. Por isso, diz Nietzsche ([1888] 2006, III, \$ 5), "receio que não nos livraremos de Deus, pois ainda cremos na gramática..."

Ao analisar a idiossincrasia dos filósofos, dentre eles a já mencionada falta de sentido histórico, Nietzsche ([1888] 2006, III, \$4) diz que uma delas é confundir o último e o primeiro: tomam os "conceitos mais elevados" e mais gerais como o começo, quando na verdade eles aparecem apenas no fim. E isso justamente porque a crença na oposição de valores impede que admitam que algo elevado pode ter surgido de algo baixo. Em contrapartida, Nietzsche ([1888] 2006, III, \$ 5) afirma que ao trazermos à consciência os pressupostos da metafísica da linguagem, isto é, da razão, é precisamente essa metafísica que em toda parte vê agentes e atos, pois: 
[...] acredita na vontade como causa; acredita no "Eu", no Eu como ser, no Eu como substância, e projeta a crença no Eu-substância em todas as coisas apenas entáo cria o conceito de "coisa"... Em toda parte o ser é acrescentado pelo pensamento como causa, introduzindo furtivamente; apenas da concepçấo "Eu" se segue, como derivado, o conceito de "ser"... (NIETZSCHE, [1888] 2006, III, $\$ 5$, grifos do autor).

Pêcheux e Orlandi, ao estabelecerem uma análise não-subjetiva da subjetividade, criticam as teorias idealistas do sujeito, crítica ao que Nietzsche chama de crença metafísica no sujeito, no eu. Criticam assim que o sujeito seja a origem do sentido, e que a linguagem possa ser atravessada por esse sujeito. Ao contrário disso, propóem que o sujeito está constituído pelo simbólico e no simbólico. O sujeito, para essa perspectiva, é um efeito da linguagem, ou seja, é porque imerso na linguagem que o sujeito pode se pensar como sujeito. Efeito da gramática, que apresenta o sujeito como aquele que realiza uma ação, que se apresenta como origem dessa ação.

Pêcheux (1975), ao dizer o sujeito enquanto efeito de linguagem, afirma que se trata de um teatro egoico: à pergunta "quem é?", responde-se evidentemente "sou eu", ao que se soma uma variada sorte de evidências: eu penso, ajo, ouço. Esse funcionamento evidente do eu ressoa a perspectiva nietzscheana de que a causa do predicado penso é um eu. Mas, para Pêcheux ([1975] 1995), trata-se de um processo ideológico: o processo de identificaçáo do sujeito com uma formaçáo discursiva - "[...] sob a evidência de que "eu sou realmente um eu" [...], há o processo da interpelaçáo-identificação que produz o sujeito no lugar deixado vazio: "aquele que...", isto é, X, o qüidam que se achará aí; e isso sob diversas formas, impostas pelas "relaçôes sociais jurídico-ideológicas" (PÊCHEUX, [1975] 1995, p. 145, grifos do autor).

Em Semântica e Discurso ([1975] 1995), Michel Pêcheux empreende um longo percurso para criticar a concepção de sujeito do que chama de tendência lógico-formalista na linguística. Cita Louis Althusser em Aparelhos Ideológicos do Estado (1970) para afirmar ser o sujeito a evidência ideológica primeira:

Como todas as evidências, inclusive as que fazem com que uma palavra "designe uma coisa" ou "possua um significado" (portanto inclusive as evidências da transparência da linguagem), a evidência de que vocês e eu somos sujeitos - e até aí não há problema - é um efeito ideológico, o efeito ideológico elementar (PÊCHEUX, 1975, p. 32). 
Apesar então de Pêcheux, na retomada de Althusser, atribuir ao ideológico o efeito-sujeito, não podemos deixar de ver a ressonância com Nietzsche.

Ao tratar da relação entre teoria do conhecimento e filosofia da linguagem, Pêcheux demonstra de que modo o problema do sujeito, enquanto causa de um predicado, estava presente em Immanuel Kant, e assim a categoria de subjetividade, que "[...] aparece na reelaboração que Kant e seus sucessores fazem da oposição aristotélica contingente/necessário, através da questão da inerência do predicado ao sujeito (ou conceito) ao qual ele se aplica" (PÊCHEUX, [1975] 1995, p. 47). E é exatamente contra essa posição, que Pêcheux identifica em Kant, que tanto ele quanto Nietzsche produzem uma crítica. Citando a Crítica da Razáo Pura (1781), Pêcheux ([1975] 1995) retoma a distinção kantiana entre juízos analíticos e juízos sintéticos:

Em todos os juízos em que se pensa a relaçáo de um sujeito com um predicado [...], essa relação é possível de duas maneiras: ou o predicado B pertence ao sujeito A como algo que está contido (implicitamente) no conceito A, ou B está inteiramente fora do conceito A, ainda que esteja, na verdade, em conexão com ele. No primeiro caso, eu nomeio o juízo como analítico; no outro, como sintético (PÊCHEUX, [1975] 1995, p. 47, grifos do autor).

É exatamente a essa superstição lógica que Nietzsche dirige sua crítica. Pêcheux, na esteira nietzscheana, também empreende sua crítica ao que ele chama de as bases comuns do pensamento moderno, ao que vem se ligar isso que ele caracteriza como a corrente lógico-formalista na Linguística.

Nessa corrente, Pêcheux compara o pensamento de E. Husserl com o de G. Frege, ao estabelecer a diferença entre ambos no que tange à relaçáo do sujeito com as suas representaçóes. Para Husserl, segundo Pêcheux, trata-se da subjetividade como fonte e princípio de unificação das representaçôes, enquanto que a concepçáo fregeana é a de que o sujeito é portador das representaçóes. Pêcheux afirma ainda que a primeira concepçáo domina e recobre a primeira, "a tal ponto que o mito da criação e do autor (o "eu" único que se exprime etc.) aparece como o duplo literário da subjetividade filosófica" (PÊCHEUX, [1975] 1995, p. 53), a ponto de a subjetividade se tornar ao mesmo tempo o excedente contingente que transborda o conceito e a condiçấo de expressão do conceito. 


\section{Outra temporalidade: Nietzsche-Sapir-Humboldt}

Wilhelm von Humboldt visa a compreender a formação progressiva da gramática no espírito humano, principalmente como nasce em uma língua o que o autor chama de modo particular de representaçáo das relaçóes gramaticais (forma), e quais os efeitos dessas relaçóes serem representadas de uma maneira ou de outra para o pensamento e para o desenvolvimento de ideias. A linguagem em Humboldt é uma faculdade que se desenvolve progressivamente, constituindo-se como um instrumento, instrumento este que apresenta certa "disposição virtual" para usos diversos. Em Nietzsche, a gramática aparece como a questão da apresentação de um juízo, na relação sujeito e predicado, enquanto em Humboldt a gramática se coloca com relação às formas gramaticais, ou seja, de que modo ao mudar a forma gramatical de língua para língua, essa mudança afeta a cognição.

Nietzsche visa a, dentre outros aspectos, compreender de que modo a linguagem influencia nossas crenças morais e nossos juízos de valor. Nesse contexto, a gramática determina os modos de filosofar. Afirma Nietzsche ([1886] 2005) que:

[...] filósofos do âmbito linguístico uralo-altaico (onde a noção de sujeito teve o desenvolvimento mais precário) com toda a probabilidade olharáo "para dentro do mundo" de maneira diversa e se acharão em trilhas diferentes das dos indos-germanos ou mulçumanos: o encanto exercido por determinadas funçôes gramaticais é, em última instância, o encanto de condições raciais e juízos de valor fisiológicos. (NIETZSCHE, [1886] 2005, \$20, grifos do autor).

Desse modo, esses pensamentos filosóficos não seriam tanto uma descoberta, mas um reconhecimento. Reconhecimento de raciocínios derivados do sistema linguístico. Por outro lado, "não basta utilizar as mesmas palavras para compreendermos uns aos outros; é preciso utilizar as mesmas palavras para a mesma espécie de vivências interiores, é preciso, enfim, ter a experiência em comum com o outro" (NIETZSCHE, [1886] 2005, \$268, grifos do autor).

A relação privilegiada com o pensamento caracteriza o que seja linguagem em Humboldt. Dessa maneira, o pensamento é representado pela linguagem: palavras e relaçóes gramaticais concorrem para representar o pensamento. Nesse contexto, Humboldt afirma algumas línguas como supe- 
riores a outras, pois algumas estariam mais aptas à expressão de certas ideias. $\mathrm{O}$ argumento leva em conta a comparação entre línguas para afirmar a superioridade das línguas flexionais. O desenvolvimento das ideias dependeria da possibilidade de se pensar certas relaçôes. Assim, uma língua indígena americana não teria o prazer pelo pensamento abstrato, e, já que é assim, seria impossível que surjam certos pensamentos em determinadas línguas. $\mathrm{O}$ que está em jogo neste tipo de raciocínio é que o pensamento, para se desenvolver em pensamento abstrato, exigiria que as relaçôes gramaticais respondessem a relaçôes lógicas. A formaçâo da linguagem e das formas abstratas do pensamento sáo indissociáveis para Humboldt. O pensamento, entáo, apenas por meio de uma operação lógica introduz nas palavras a verdadeira relaçáo gramatical pretendida, na medida em que tende a se converter em uma forma.

$\mathrm{Na}$ relação entre linguagem e pensamento, é interessante notar que, para Nietzsche, a noção de alma pode ser derivada da noção supersticiosa do sujeito e do eu, ambos como atomismos. Todas as três noções são superstiçóes populares de tempos imemoriais e, além delas, entra em cena também algum jogo de palavras e os desencaminhamentos provocados pela gramática. Dessa maneira, podemos mais uma vez compreender a força da linguagem na construçáo do mundo da experiência, e do modo como ela determina desde construçóes filosóficas, até crenças religiosas. Esse poder da linguagem de instaurar uma interpretação do mundo é tido por Nietzsche como causa, por exemplo, do erro de Descartes e de tantos outros filósofos: eles foram seduzidos pela gramática. Sendo assim, podemos dizer que a funçáo da gramática em Humboldt é positiva, pois possibilitaria o pensamento, enquanto em Nietzsche essa função é negativa, pois propicia um tipo de pensamento gregário.

Para Humboldt, quanto mais a língua imprimir formalidade, mais aumentaria a potência da faculdade de pensar. Mas, em princípio, a língua só teria signos para os objetos, e caberia ao que escuta juntar as formas que dáo nexo ao discurso. A língua deveria assim adaptar-se às necessidades do pensamento e reproduzir seu organismo em sua estrutura. Humboldt argumenta que, se não fosse assim, a língua seria apenas um símbolo imperfeito do pensamento.

Para Nietzsche, não se trata de aumentar a faculdade de pensar, pois pensar não é uma faculdade em Nietzsche. É no jogo com a consciência que exerce a linguagem um papel decisivo. Diz Nietzsche ([1882] 2008, \$354) que o problema da consciência, de o homem tornar-se consciente, apenas 
adquire contornos específicos quando pensamos em que medida o homem poderia existir sem ela, pois, para Nietzsche, poderíamos pensar, sentir, querer, recordar, e até mesmo agir, e para nada disso precisaríamos de ter consciência. Toda a vida poderia ser possível sem que ela fosse consciente, "sem que, por assim dizer, ela se olhasse no espelho" (NIETZSCHE, [1882]2008, $\$ 354)$, já que, ainda hoje, boa parte de nossa vida se passa sem ter-se consciência dela. A partir disso, ele se pergunta "para que então consciência, quando no essencial é supérflua?” (NIETZSCHE, [1882] 2008, \$354). A resposta de Nietzsche a esta pergunta está diretamente ligada à necessidade de comunicaçáo, que por sua vez está ligada à capacidade de comunicação. Ao supor que essa seja uma hipótese válida, Nietzsche conjectura que a consciência se desenvolveu sob a pressáo da necessidade de se comunicar, que ela foi necessária e útil somente entre duas pessoas - em especial, entre uma pessoa que manda, e outra que obedece. "Consciência é, na realidade, apenas uma rede de ligação entre as pessoas, - apenas como tal ela teve que se desenvolver: um ser solitário e predatório não necessitaria dela” (NIETZSCHE, [1882] 2008, \$ 354). Que nossas ações, pensamentos, movimentos e mesmo sentimentos tenham chegado à consciência ao menos em parte, é fruto de que o homem precisava de ajuda e proteçáo de seus iguais, e para isso precisava exprimir o perigo em que se encontrava e precisava que fosse compreendido, já que, dentre os animais, era a espécie mais ameaçada. E, segundo Nietzsche, para todas essas açóes o homem precisava "saber" o que faltava, necessitava "saber" o que sentia, "saber" o que pensava, ou seja, o homem necessitava antes de tudo de consciência. Como toda criatura viva, o homem pensa continuamente, mas náo sabe que pensa. $\mathrm{O}$ pensar consciente, o pensar que ele sabe que pensa, "é apenas a parte menor; a mais superficial, a pior, digamos: - pois apenas esse pensar consciente ocorre em palavras, ou seja, em signos de comunicaçáo, com o que se revela a origem da própria consciência” (NIETZSCHE, [1882] 2008, \$354). Quando Nietzsche fala de consciência, lembra que ela não é a razão, trata-se apenas do tomar-consciência-de-si da razão, e, nesse sentido, andam de mãos dadas o desenvolvimento da linguagem e o desenvolvimento da consciência.

Nesse sentido, diferenciam-se sobremaneira Nietzsche e Humboldt. Para Nietzsche a linguagem é uma ponte entre um ser humano e outro, mas não só ela: também cumpre esse papel o olhar, o toque, o gesto. Em suma, é na medida em que cresce a necessidade de comunicaçáo que aumentam a consciência e a linguagem: "o homem inventor de signos é, ao mesmo tempo, o homem cada vez mais consciente de si” (NIETZSCHE, [1882] $2008, \$ 354)$. 
Em muitos manuais de Linguística, Humboldt é tido como uma espécie de precursor de Edward Sapir. Veremos, entretanto, que a relação que pode ser estabelecida entre Nietzsche e Sapir, mas que não pode ser estabelecida entre Humboldt e Nietzsche, estabelece uma diferença entre Sapir e Humboldt.

A linguagem, tanto para Edward Sapir quanto para Nietzsche, não é inerente ao homem. Ela foi criada, no sentido de que náo faz parte das funçôes bio-fisiológicas da espécie humana. Por mais que para Nietzsche a linguagem seja uma transposição de metáforas do corpo, não se trata de biologismo. Para Nietzsche, é por necessidade de comunicação que o homem cria a linguagem, pois enquanto espécie animal mais ameaçada, precisou de algo que pudesse se sobrepor aos animais. Para Sapir, dizer que a linguagem é não-inerente significa dizer que ela é uma função cultural, e não função biológica, como andar, por exemplo. A linguagem em Sapir é adquirida, enquanto o ato de andar é algo previsto pela biologia humana: se o homem não estiver em sociedade, ele não aprenderá a falar, mas com toda certeza, aprenderá a andar. $\mathrm{O}$ caráter, por assim dizer, social da linguagem aparece nos dois autores. Dizer do caráter criador da linguagem liga tanto Nietzsche quanto Sapir a uma determinada tradição, para a qual a linguagem é uma arte, um artefato. Obviamente o corpo humano está biologicamente preparado para a linguagem, mas é só por necessidade, em Nietzsche, ou apenas porque é transmitida, em Sapir, que a linguagem pode ser "adquirida". Para Nietzsche, o desenvolvimento da linguagem e o desenvolvimento da consciência andam de mãos dadas, pois um ser solitário e predatório não necessitaria nem de linguagem, nem de consciência. Sapir (2004, p. 12), por sua vez, afirmará que "nós vemos esse processo complexo de interação da linguagem e do pensamento tomando lugar sob nossos olhos", pois o instrumento-linguagem torna o produto-pensamento possível, enquanto o último refina o primeiro.

Nesse ponto, a diferença é necessariamente uma diferença de força. Em Nietzsche, linguagem e consciência aparecem para que a espécie humana consiga sobreviver. Ao uniformizar as designaçóes, diz Nietzsche que o homem pode se livrar do estado de guerra que o colocava em risco. Em Sapir, por mais que a linguagem comece, segundo ele, de modo pré-racional, não se trata de luta por afirmação de vontade. Por mais que para ambos ajam na linguagem forças irracionais e inconscientes, de modo que para os dois autores a maior parte da linguagem se dá nesse nível, novamente em Nietzsche essas forças irracionais lutam no homem com intuito de que ele as afirme, enquanto para Sapir essas forças se referem aos instintos humanos. 
Nessa relação, tanto para Sapir quanto para Nietzsche a linguagem cumpre o papel de vulgarizar a experiência por meio de um movimento que ambos identificam: a igualação do não-igual. Segundo Sapir, a experiência do homem com as coisas é incomunicável. A experiência individual que se tem com o lugar em que se mora indiscutivelmente será chamado de casa. Entretanto, casa é o conceito que iguala todas as experiências individuais com ela, de modo que é preciso equalizar essa experiência individual com a noção conceitual coletiva, entâo a palavra aparece com símbolo de um conceito, ou seja, uma cápsula de pensamento convencional. Desse modo, o fluxo infinito da experiência, diferente entre si porque individual, é designado igualmente por todos. Nietzsche, nesse mesmo caminho, afirma que “toda palavra é um pré-conceito" (NIETZSCHE, [1879] 2008, \$ 55) e nisso consiste o perigo da linguagem para a liberdade espiritual, pois, se bem e mal são os preconceitos divinos (NIETZSCHE, [1882] 2008, § 259), o são porque palavras encaminham o sentido da experiência no mundo.

A linguagem vulgariza as experiências individuais inclusive porque faz com que o homem enxergue oposiçóes onde existem apenas gradaçóes. Nas ideias nietzscheanas sobre a linguagem, as antonímias são as maiores armas dos metafísicos, pois apagam as cores do mundo e o pintam de branco e preto, cristalizando e naturalizando a oposição, por exemplo, de bem e mal. A filosofia de Nietzsche, a filosofia histórica, no entanto, constata que não existem opostos. O método genealógico, ao dar história às coisas, demonstra que a oposição é sempre fruto de um esquecimento. Sapir (2004, p. 78) também critica o binarismo no qual a linguagem aprisiona o homem, ao dizer que "uma vez que temos em mente que todas as coisas sejam definitivamente boas ou más ou definitivamente pretas ou brancas, é difícil conceber que cada coisa particular pode ser boa E ruim (em outras palavras, indiferente)". Argumenta Sapir que não podemos estar contentes com essa "função" da linguagem, pois não há razáo inerente para que os conceitos se organizem dessa maneira.

O poder de fixação da linguagem para Sapir se liga ao fato que a forma vive mais que o seu conteúdo conceitual. Isto é, tanto a forma quanto o conteúdo estáo sempre mudando, mas a forma tende a demorar mais onde o "espírito" já se foi. A palavra "esposa", por exemplo, se mantém há muito tempo, enquanto seu conteúdo conceitual mudou. Para Nietzsche, a linguagem possui esse poder cristalizador também porque "se a forma é fluida, o "sentido" é mais ainda..." (NIETZSCHE, [1887] 2004, II, \$ 12). Para Nietzsche, os sentidos e as finalidades são obliterados, e por meio desse apagamento uma nova vontade pode se assenhorar de outra, pois "toda 
a história de uma "coisa", um órgão, um uso, pode desse modo ser uma ininterrupta cadeia de signos de sempre novas interpretaçóes e ajustes, cujas causas nem precisam estar relacionadas entre si, antes podendo se suceder e substituir de maneira meramente casual" (NIETZSCHE, [1887] 2004, II, $\$ 12)$. Dessa maneira, para Sapir e para Nietzsche, o obliteramento sucessivo do conteúdo conceitual produz o efeito de rigidez da linguagem.

Essa amálgama de classificaçôes age de modo tão radical que, para Sapir e Nietzsche, a língua que falamos determina nossa apreensão do mundo por meio de hábitos linguísticos. Isso quer dizer que a linguagem, enquanto já interpretação dos fenômenos, impóe uma forma de apreender a realidade. O termo hábitos linguísticos, segundo J. Penn ${ }^{5}$, não está em W. von Humboldt, a quem é atribuído uma das bases germânicas para a hipótese Sapir-Whorf. Em princípio, portanto, podemos atribuir o uso do termo por Sapir a Nietzsche. Existem então funcionamentos da linguagem que agem na forma como compreendemos o funcionamento do mundo.

Para Sapir, a linguagem é um caminho interpretativo e não uma roupagem, pois o pensamento é formado por um conteúdo latente de linguagem ao mesmo tempo em que para se formar interpreta esse fluxo. A linguagem em Sapir é como uma sociedade pensa, enquanto o pensamento é o quê uma sociedade pensa. Nesses termos, uma sociedade que náo conhece a teosofia não terá um nome para isto, do mesmo modo, exemplifica Sapir, os aborígenes, que náo conheciam o cavalo, precisaram inventar ou mesmo tomar emprestada uma palavra para designá-lo. $\mathrm{O}$ vocabulário de uma língua, portanto, mais ou menos reflete sua cultura, mas em Sapir náo se pode identificar a língua com um dicionário da cultura, pois a questáo é que ambas se desenvolvem em paralelo. Para Sapir, uma língua é mais ou menos propícia a um tipo de atividade e a um determinado tipo de ideia.

Aqui novamente Nietzsche e Sapir se aproximam, pois, para Nietzsche, conforme já citamos, filósofos do ramo linguístico uralo-altaico, que segundo ele teve a noção de sujeito precariamente desenvolvida,

olharão 'para dentro do mundo' de maneira diversa e se acharão em trilhas diferentes das dos indos-germanos ou mulçumanos: o encanto exercido por determinadas funçôes gramaticais é, em última instância, o encanto de condiçôes raciais e juízos de valor fisiológicos (NIETZSCHE, [1886] 2005, § 20).

\footnotetext{
${ }_{5}^{5}$ PENN, J. M. Linguistic Relativity versus Innate Ideas. The origins of the Sapir-Whorf
} Hypothesis in German Thought. Mouton: Paris, 1972. 
Segundo O. Giacóia ${ }^{6}$, Nietzsche não está se referindo apenas à filosofia tal como a compreendemos, mas a todo o saber especulativo que, de um modo impressionante, estaria em relação de arbitrariedade. A gramática de uma determinada língua daria ao filósofo um conjunto de sistemas possíveis e, se examinarmos os principais conceitos da filosofia, veremos bastante semelhanças.

Quando tomamos Chang Tung-Sun ${ }^{7}$ e sua $A$ teoria do conhecimento de um filósofo chinês, temos uma boa explicação para isso. Afirma Tung-Sun que os problemas filosóficos do Ocidente não eram os mesmos da filosofia chinesa. Enquanto a filosofia ocidental herdeira de Kant acreditava ter encontrado as categorias universais, toda ela não passa de uma forma de conhecimento, que se limita a um determinando tempo e a uma determinada sociedade. A base desse "erro" identificado por Tung-Sun está, um dos fatores, nas diferentes gramáticas. $\mathrm{O}$ chinês não possui o tipo tradicional de proposição "sujeito-predicado" que caracteriza as línguas indo-europeias, portanto os filósofos chineses desconhecem a noçáo de substância, donde conclui que "muitos problemas filosóficos são apenas problemas de linguagem” (TUNG-SUN, 1994, p. 179).

Por mais parentescos que os dois autores guardem entre si, há uma diferença fulcral entre eles, que diferencia em grande medida os dois projetos. Há uma diferença de força. Nietzsche funda sua crítica à moral na crítica à linguagem, enquanto Sapir está interessado, a despeito disso, em conseguir descrever as línguas. Para efetuar essa "descrição", Sapir se funda em uma concepçáo de linguagem, que em muitos pontos se assemelha a Nietzsche.

\section{Consideraçóes Finais}

No intervalo entre as Ciências da Linguagem e a Filosofia é que tem lugar um trabalho sobre as filiaçôes a Nietzsche nas Ciências da Linguagem. Quando nos colocamos esta questáo, entendendo Nietzsche enquanto um acontecimento ${ }^{8}$, como aquilo que instaura temporalidades, buscamos compreender a futuridade desse acontecimento, ou seja, aquilo que da enuncia-

${ }^{6}$ GIACÓIA, O. Cinco aulas sobre Nietzsche. Aula 5. Cefet-Sp. Disponível em: http://www. rubedo.psc.br

7 TUNG-SUN, C. A teoria do conhecimento de um filósofo chinês. In: CAMPOS, H. [org.] Lógica, poesia, linguagem. Textos traduzidos por Heloysa de Lima Dantas. 3. ed. São Paulo: Edusp, 1994.

${ }^{8}$ GUIMARÃES, E. Semântica do acontecimento. 2. ed. Campinas: Pontes, 2005. 
ção nietzscheana havia se projetado no futuro que instaurou.

Pontilhando em linha reta, chegamos ao que ficou conhecido como Hipótese Sapir-Whorf (HSW). Nossa investigação nos fez compreender que a HSW não havia sido formulada univocamente. Não há "uma" Hipótese Sapir-Whorf. Esse termo, inclusive, foi cunhado em 1954, por Harry Hoijer, na ocasiáo de um congresso nos Estados Unidos, após a morte dos autores que a ela deram o nome. Os autores, inclusive, nunca foram exatamente próximos.

A filiação de Sapir a Nietzsche está materializada, principalmente, pela ideia de hábito gramatical - nas palavras de Nietzsche, grammatischen Gewohnheit, em Sapir, language habits. Ideia que, inclusive, não aparece em Whorf, nem em Humboldt, e aparece claramente em Nietzsche. O hábito gramatical diz respeito à ideia de que há algo do gramatical que nos constitui de tal maneira que comparece em raciocínios cotidianos, também filosóficos.

A filiação entre Nietzsche e Sapir, a partir do momento em que foi estabelecida, recortou um memorável: Guilherme de Humboldt. A história oficial da Linguística o apresenta como precursor da Hipótese Sapir-Whorf. Isso nos levou a pensar que, se Humboldt era lido como seu precursor, poderia haver algo de Humboldt em Nietzsche, e assim teríamos, no estabelecimento de temporalidades, o recorte efetuado pelo presente futuro de um memorável. Tratava-se também de compreender se o que havia entre Nietzsche e Sapir não era exclusivamente o que já haveria entre Humboldt e Nietzsche, e assim entre Humboldt e Sapir. Não foi isso, entretanto, que as análises nos levaram a concluir.

As análises sobre a filiação de Nietzsche a Humboldt nos levaram a concluir que, apesar de ambos colocarem a relação entre linguagem e "pensamento" entre suas preocupaçôes, é no que tange à consideração do simbólico que pode ser vista alguma aproximação entre eles. Não ao ponto, entretanto, de se falar que Humboldt condiciona a reflexão de Nietzsche sobre a linguagem? .

A despeito dessa temporalidade, havia ainda outro caminho de investigação, que não fazia parte dessa mesma futuridade projetada em Sapir. Tratava-se da obra de Michel Pêcheux. Encontramos menções a Nietzsche em três ou quatro momentos da obra de Michel Pêcheux. Particularmen-

9 Ironicamente, Nietzsche chama Humboldt de "o nobre cabeça chata". "Wilhelm von Humbold $<t>$, der edle Flachkopf”. eKGWB/NF-1888,16[61] — Nachgelassene Fragmente Frühjahr-Sommer 1888. 
te, chamou-nos bastante atenção uma passagem sobre Pêcheux, na obra L'inquiétude du discours, de Denise Maldidier: "ele ia reler Nietzsche". É bastante trivial que, se ele iria reler, já havia lido anteriormente. Aliado a isso, encorajou-nos bastante saber que no Institute Mémoires de l'Édition Contemporaine, onde está depositado o espólio de Pêcheux, havia uma pasta chamada Projets Nietzsche. Há entáo uma materialidade configurada de outra maneira nessa filiação, diferente da materialidade dos laços produzidos por palavras, como no caso de Sapir e Nietzsche.

Essas idas e vindas das temporalidades são estabelecidas pela própria enunciação, ou seja, um texto que vem no tempo depois pode fazer reinterpretar certos sentidos que estavam no tempo antes. É característico do acontecimento que ele instaure temporalidades, e o que nossas análises demonstram é que a futuridade que acontecimento projeta é equívoca, ou seja, há algo no acontecimento que permite que sua latência de futuro seja Sapir e seja Pêcheux.

Essas duas temporalidades parecem, à primeira vista, bastante contraditórias, e em alguma medida o são ${ }^{10}$. Enquanto Humboldt e Sapir produzem a reflexão a partir de uma posiçáo que podemos chamar de culturalista, Pêcheux escreve sob a perspectiva histórica. Em comum, entretanto, nas duas temporalidades há um peso relevante para o simbólico. Quer dizer, ao passo que é bastante dominante nas Ciências da Linguagem a posição biologizante da linguagem, aquela que tem seu representante máximo em Noam Chosmky, as duas temporalidades que descrevemos refletem a linguagem a partir do que nela há em relação ao simbólico, enquanto sistema de representaçôes. Em Pêcheux, entretanto, esse sistema nunca se fecha, e não é homogêneo, como em Sapir.

As diferentes temporalidades que o nome de Nietzsche constitui para as Ciências da Linguagem são possibilitadas pelas particularidades enunciativas da prosa nietzscheana, no que tem capital importância o trabalho da/ na polifonia e do/no silêncio.

Essas duas temporalidades que descrevemos nas Ciências da Linguagem nos encaminham a pensar, além das descontinuidades da História, a própria pluralidade da coexistência temporal. Ou seja, quando lidamos com a História das Ideias Linguisticas, não há primeiro uma coisa, depois outra,

\footnotetext{
${ }^{10}$ Essa conclusão particularmente me interessa no que concerne a sua semelhança, nesse microcosmo, com os trabalhos de Foucault. Foucault foi mestre em demonstrar que aquilo que na superfície se contradiz, se pensado em termos de descontinuidade náo se opóem veementemente.
} 
depois outra. O presente demanda sentido e é a partir dessa demanda presente que passamos a interrogar o passado.

A possibilidade de pensar as temporalidades em sua equivocidade me leva a crer que há um caminho na reflexão sobre a linguagem a ser trilhado nas sendas de algo que possa ser dito como um caminho ao materialismo trágico - a consideração de que a determinação histórica não é fruto de um processo maquínico, motorizado, mas que há algo do acaso que comparece, e que nesse acaso, intervalo entre o equívoco e a linguagem, temos ainda um espaço para a arte, para a criação, para r-existir ao sedentarismo dos sentidos.

\section{Referências}

CHATTERJEE, R. Before and beyond Linguistics: Professor Nietzsche, Philologist. In: NICHOLSON, C.; CHATTERJEE, R. Tropic crucible: self and theory in language and literature. Kent Ridge, Singapore: Singapore University Press, 1984.

DELEUZE, G.; GUATTARI, F. [1980] Mil platôs: capitalismo e esquizofrenia. Tradução de Ana Lúcia de Oliveira. Rio de Janeiro, RJ: Editora 34, 2000 .

FOUCAULT, M. Les mots et les choses: une archeologie des sciences humaines. Paris: Gallimard, 2012.

. Microfisica do poder. 24. ed. Rio de Janeiro, RJ: Graal, [1978] 2008.

GUIMARÁES, E. Domínio Semântico de Determinação. In: GUIMARÃES, E.; MOLLICA, M. C. (org.). A palavra - forma e sentido. Campinas: Pontes Editores, RG Editores, 2007.

História da Semântica. Campinas: Pontes, 2004.

Seminário Avançado de Semântica. IEL. 2009/2. 
. Semântica do acontecimento. 2. ed. Campinas: Pontes, 2005a.

. Textualidade e Enunciação. Revista Escritos. n. 2. Labeurb/Nudecri: 2002.

. Texto e enunciação. Revista Organon, UFRGS. 1995.

. Os limites do sentido: um estudo histórico e enunciativo da linguagem. 3. ed. Campinas, SP: Pontes, 2005b.

. Texto e argumentaçáo: um estudo de conjunçôes do português.

4. ed. Campinas, SP: Pontes, [1987] 2007.

GADET, F.; HAK, T. [Org.]. Por uma análise automática do discurso: uma introduçáo à obra de Michel Pêcheux. 3. ed. Campinas, SP: UNICAMP, 1997.

HUMBOLDT, W. v. Sur le caractère national des langues, et autres écrits sur le langage. Textes choisis par Denis Touard. Paris : Points Essais, 2012.

MALDIDIER, Denise. L'inquiétude du discours. Textes de Michel Pêcheux choisis et présentés par Denise Maldidier. Paris : Editions des Cendres, 1990.

NIETZSCHE, F. Aurora. Companhia das Letras: São Paulo, [1881; 1887] 2004.

2004 .

. Genealogia da moral. Companhia das Letras: São Paulo, [1887]

. Verdade e mentira no sentido extra-moral. In: Nietzsche, Obras

Incompletas. Tradução de Rubens Torres Filho. Coleçâoo Os pensadores. São Paulo: Nova Cultural, [1873] 2005. 
. Humano, demasiado humano. Um livro para espíritos livres. São Paulo: Companhia das Letras, [1878; 1886] 2005.

Além do bem e do mal. Prelúdio a uma filosofia do futuro. São Paulo: Companhia das Letras, [1886] 2005.

Crepúsculo dos Ídolos. Ou como se filosofa com o martelo. Companhia das Letras: São Paulo, [1888] 2006.

A Gaia Ciência. Um livro para espíritos livres. São Paulo: Companhia das Letras, [1882; 1887] 2008.

Humano, demasiado humano II. Um livro para espíritos livres. São Paulo: Companhia das Letras, [1879; 1880; 1886] 2008.

ORLANDI, E. [org.] História das Ideias Linguísticas - construção do saber metalinguístico e constituiçáo da língua nacional. Cáceres, Campinas: Pontes, Unemat Editores, 2001.

A linguagem e seu funcionamento: as formas do discurso. Campinas, SP: Pontes, [1987] 2007.

Terra à vista: discurso do confronto - velho e novo mundo. 2. ed. Campinas, SP: Editora da UNICAMP, [1990] 2008.

PÊCHEUX, M. Semântica e Discurso. 2. Ed. Traduçấo Eni Orlandi. Campinas: Editora da Unicamp, 1995.

SAPIR, E. Language. An introduction to the study of speech. New York: Harcourt, Brace, 2004.

Recebido: 05/11/2018

Aceito: 21/01/2019

DOI: $10.5902 / 2179219435471$ 